\title{
Successful Direct Adsorption of Lipoproteins (DALI) Apheresis During Pregnancy in an Omani Woman with Homozygous Familial Hypercholes- terolemia
}

\author{
Tamima Al-Dughaishi ${ }^{1}$, Khalid Al-Waili ${ }^{2}$, Yajnavalka Banerjee ${ }^{3}$, Shahila Sheik ${ }^{1}$, Hilal Al-Sabti ${ }^{4}$, \\ Ibrahim Al-Zakwani ${ }^{5,6}$, Suad Al-Mukhaini ${ }^{7}$, Khalifa Al Wahaibi ${ }^{8}$, Ali T. Al-Hinai ${ }^{9}$ and Khalid \\ Al-Rasadi ${ }^{2, *}$ \\ ${ }^{I}$ Department of Obstetrics \& Gynecology, Sultan Qaboos University Hospital, Muscat, Oman \\ ${ }^{2}$ Department of Clinical Biochemistry, Sultan Qaboos University Hospital, Muscat, Oman \\ ${ }^{3}$ Department of Biochemistry, College of Medicine \& Health Sciences, Sultan Qaboos University, Muscat, Oman \\ ${ }^{4}$ Department of Surgery, Cardiothoracic Unit, Sultan Qaboos University Hospital, Muscat, Oman \\ ${ }^{5}$ Department of Pharmacology and Clinical Pharmacy, College of Medicine \& Health Sciences, Sultan Qaboos \\ University, Muscat, Oman \\ ${ }^{6}$ Gulf Health Research, Muscat, Oman \\ ${ }^{7}$ Department of Nursing, Sultan Qaboos University Hospital, Muscat, Oman \\ ${ }^{8}$ Department of Surgery, Vascular Unit, Sultan Qaboos University Hospital, Muscat, Oman \\ ${ }^{9}$ Ministry of Health, Muscat, Oman
}

\begin{abstract}
We report our experience with Direct Adsorption of Lipoproteins (DALI) apheresis in an Omani pregnant woman affected by homozygous familial hypercholesterolemia. To the best of our knowledge this is the first successful pregnancy treated with DALI apheresis.

The patient had a history of coronary artery disease, supra-aortic valvular stenosis and severe carotid artery disease with right carotid artery stenting. She was on a regular biweekly DALI apheresis since 2008. In May 2013, she became pregnant and rosuvastatin and ezetimibe were stopped while she continued on DALI apheresis biweekly. This treatment during pregnancy was successful with no major complications. The average low-density lipoprotein cholesterol reduction during therapy was $50 \%$. She spontaneously delivered a healthy male infant $(2,400 \mathrm{~g})$ at 37 weeks. We showed that DALI apheresis therapy was safe during pregnancy with a good outcome for both mother and neonate.
\end{abstract}

Keywords: Familial hypercholesterolemia, low density lipoprotein receptor, xanthoma, LDL-apheresis, pregnancy.

\section{INTRODUCTION}

Homozygous Familial Hypercholesterolemia (HoFH) is an inherited disease caused by genetic defects in low-density lipoprotein receptors (LDLRs), apolipoprotein B (Apo B) and proprotein convertase subtilisin/kexin type 9 (PCSK9) $[1,2] \mathrm{HoFH}$ is characterized by very high levels of lowdensity lipoprotein cholesterol (LDL-C) and if not recognized and treated early it will lead to severe cardiovascular disease (CVD) early in life [3-5] HoFH is treated by combination of statin with or without ezetimibe and regular LDL apheresis [6-15].

*Address correspondence to this author at the Department of Clinical Biochemistry, Sultan Qaboos University Hospital, PO Box 38, Al-Khodh, PC-123, Sultanate of Oman, Tel: +968-96780908; Fax: +968-24141786; E-mail:khalid77@squ.edu.om
High concentrations of LDL-C levels during pregnancy may have serious consequences for both the fetus and mother. It may increase the risk of acute myocardial ischemia for women who have underlying coronary artery disease (CAD) [6-19] and it may cause fetal intrauterine growth restriction [20-22]. The use of statins is contraindicated during pregnancy and LDL apheresis should be considered in the management of pregnant women with HoFH.

There are several reported cases of successful pregnancy with $\mathrm{FH}$ treated with plasma exchange [23, 24], heparin extracorporeal LDL-C precipitation (HELP) [25, 26], or dextran sulphate-cellulose adsorption (DSA) [27, 28], cascade filtration system [29] and immunoadsorption (IA) [30] apheresis. For direct adsorption of lipoproteins (DALI) apheresis, there was one reported case of apheresis therapy 


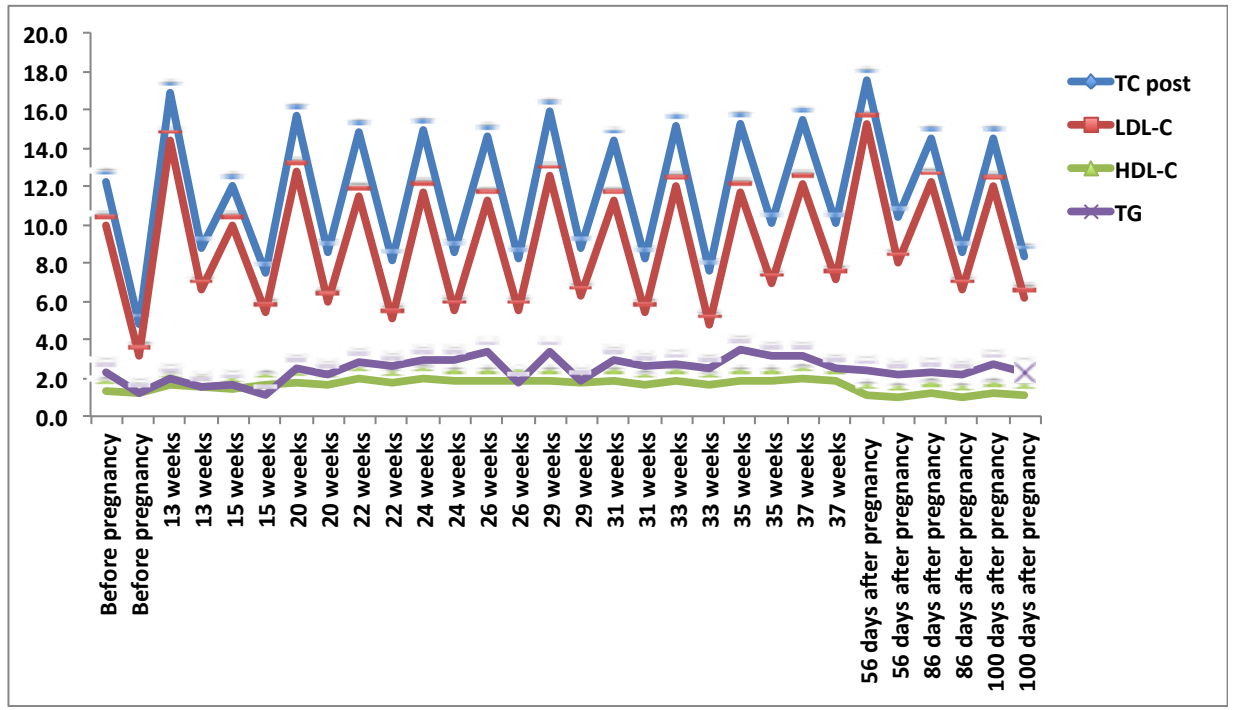

Fig. (1). Lipid levels pre and post LDL-apheresis before, during and after pregnancy.

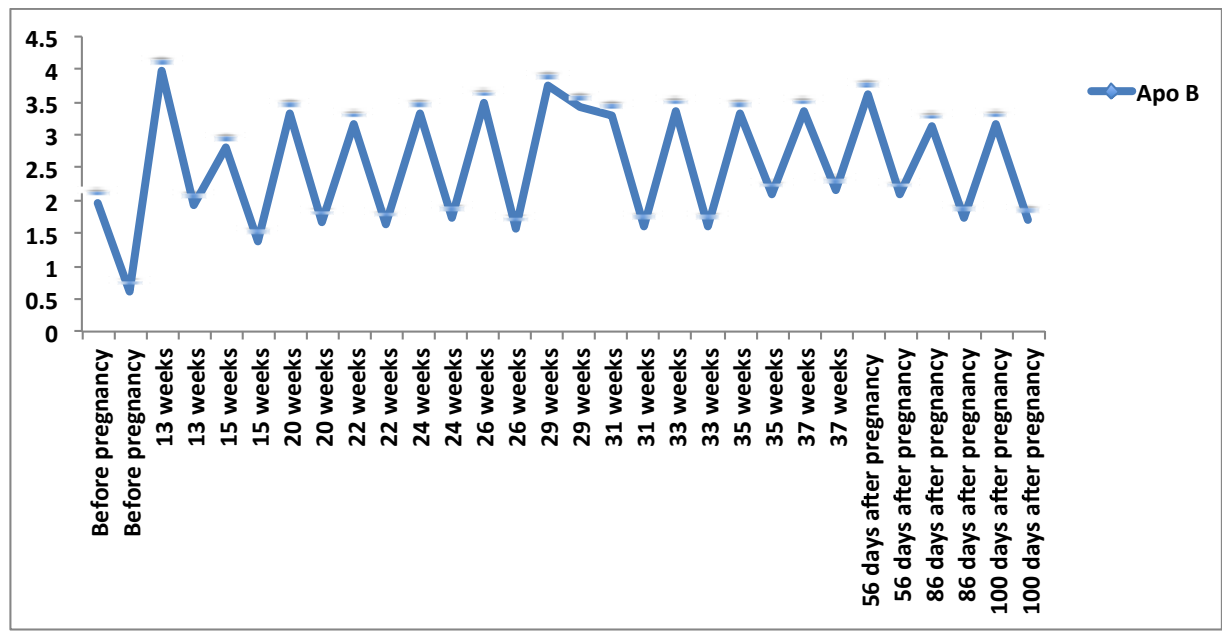

Fig. (2). Apo B levels pre and post LDL-apheresis before, during and after pregnancy.

during pregnancy but the treatment was not successful and was stopped at 28 weeks because of severe tetany related to treatement [31]. To our knowledge, we report the first successful pregnancy involving a HoFH patient treated with DALI apheresis.

\section{CASE REPORT}

The patient was a 38-year old woman diagnosed with HoFH with LDL-receptor mutation at exon 4 G397A and PCSK 9 mutation at exon 9 A1420G. She was on rosuvastatin $40 \mathrm{mg}$ and ezetimibe $10 \mathrm{mg}$. In addition, she was on biweekly DALI LDL-apheresis using a left arm basilic arterio-venous (A-V) shunt. She had carotid artery disease with a right carotid endarterectomy in 2004 and right carotid stent. She had moderate supravalvular aortic stenosis on echocardiogram but with normal left ventricular function and evidence of CAD on angiography in 2006 with minimal left anterior descending disease. The patient remained asymptomatic through the years and responded very well to pharmacological treatment and LDL-apheresis.

Prior to this pregnancy, she had 2 live children in good health but had lost 3 pregnancies. When she became pregnant this time, rosuvastatin and ezetimibe were discontinued while she was continued on low fat diet. Her pregnancy was managed by a multidisciplinary team consisting of obstetric, cardiology and lipid specialists. Due to her high risk background and LDL-C of $14.4 \mathrm{mmol} / \mathrm{L}$, she was continued on LDL-apheresis. All the biweekly DALI were performed with the DALI 750 adsorbers (Fresenius HemoCare Adsorber Technology GmbH, St. Wendel, Germany). In each session, an average of 7,100 $\mathrm{ml}$ of whole blood was processed in about $2 \mathrm{~h}$, at an average rate of 60 $\mathrm{ml} / \mathrm{h}$. Anticoagulation in the extracorporeal system was carried out by acid citrate dextrose (ACD-A) infusion and was first mixed with the patient's blood at a ratio of 1:20 and 
Table 1. Baseline lipid profile for the family.

\begin{tabular}{|c|c|c|c|c|c|c|}
\hline & TC $\mathbf{~ m m o l} / \mathbf{L}$ & LDL-C $\mathbf{~ m m o l} / \mathbf{L}$ & HDL-C $\mathbf{~ m m o l} / \mathbf{L}$ & TG mmol/L & Apo B g/L & Apo A1 g/L \\
\hline \hline Husband & 6.0 & 3.8 & 1.08 & 2.3 & 1.19 & 1.38 \\
\hline Wife (patient) & 16.9 & 14.4 & 1.67 & 2.0 & 3.97 & 1.79 \\
\hline Daughter 1 & 7.4 & 5.6 & 0.98 & 1.8 & 1.52 & 1.19 \\
\hline Daughter 2 & 7.7 & 5.6 & 1.24 & 0.9 & 1.26 & 1.41 \\
\hline Daughter 3 & 6.7 & 5.0 & 1.38 & 2.8 & 1.69 & 1.18 \\
\hline Son 1 & 8.4 & 6.1 & 0.73 & 3.3 & 0.87 & 1.19 \\
\hline Son 2 (New born) & 4.1 & 1.9 & & & \\
\hline
\end{tabular}

reduced to 1:40 after $1,500 \mathrm{ml}$ of blood was treated. Average calcium levels were $2.43 \mathrm{mmol} / \mathrm{L}$ and the patient was receiving oral calcium supplements before each apheresis therapy. Fetal monitoring was performed before and after DALI apheresis and no fetal heart rate abnormalities were detected. The first DALI-apheresis resulted in a $54 \%$ reduction of LDL-C levels to $6.6 \mathrm{mmol} / \mathrm{L}$.

The patient continued to receive DALI-apheresis until 37 weeks of gestation with average blood pressure (BP) 132/54 $\mathrm{mmHg}$, blood glucose $5.1 \mathrm{mmol} / \mathrm{L}$, glycosylated hemoglobin $\left(\mathrm{HbA}_{1 \mathrm{C}}\right) 6.2 \%$, weight $82 \mathrm{Kg}$ and body mass index (BMI) 36. She had uncomplicated spontaneous vaginal delivery of a healthy boy weighing 2,400 g. From Week 13 to 37 of her pregnancy, the patient received 12 DALI-apheresis to control cholesterol levels.

\section{DISCUSSION}

Pregnancy in women with $\mathrm{HoFH}$ carries risk to the mother and fetus. High maternal cholesterol may cause growth restriction, preeclampsia and miscarriage in animal and human studies [32, 33]. Pregnancy in women with $\mathrm{HoFH}$ is contraindicated and there are no clear guidelines for their management. Nevertheless, there are several reported cases in the literature of women treated with apheresis using plasma exchange, HELP, DSA, cascade filtration system and IA apheresis [23-30].

This is the first case of successful pregnancy outcome using the DALI apheresis system. A previous report with DALI apheresis was not successful and the apheresis was stopped at 28 weeks of gestation due to severe tetany but the pregnancy was carried out to term [31]. In our case and prior to the current pregnancy and the commencement of DALI apheresis, the woman had 2 healthy babies and 3 miscarriages. She was diagnosed with severe carotid artery disease, moderate supravalvular aortic stenosis and mild CAD. Although, she was counseled against undertaking pregnancy the decision after she became pregnant was to provide appropriate management of her cholesterol levels and the risk prevent further worsening of her cardiovascular disease.

The most suitable anticoagulants for apheresis during pregnancy are unfractionated low molecular weight heparin and citrate. Low molecular weight heparin has fewer side effects, is well tolerated and does not pass the blood-brain barrier [34]. In addition, apheresis or plasma exchange with citrate was also used in pregnant women $[35,36]$. In our case the use of ACD-A infusion as anticoagulant was proved to be safe with very minimal side effects of paresthesia around the mouth and the jaw during the sessions and this did not result in discontinuation of treatment.

In our lipid and LDL apheresis unit at Sultan Qaboos University hospital in Oman we have identified $5 \mathrm{HoFH}$ with molecular genetic confirmation and we have reported previously 2 of these cases including the current reported case [37-39]. We had lost one of the HoFH who was a female child with very severe $\mathrm{HoFH}$ and severe atherosclerosis. Currently four $\mathrm{HoFH}$, one heterozygous $\mathrm{FH}$ $(\mathrm{HeFH})$ with severe $\mathrm{CAD}$ and one HeFH with statin intolerance and $\mathrm{CAD}$ are receiving regular DALI apheresis in our unit.

In conclusion, this is the first case report of a successful pregnancy outcome in a patient with $\mathrm{HoFH}$ treated with DALI apheresis. In general, although pregnancy and delivery in women with $\mathrm{HoFH}$ and cardiovascular disease are hazardous and should be monitored very closely, long-term LDL apheresis seems feasible to control superimposed hyperlipidemia, cardiovascular disease, placental insufficiency and subsequent intrauterine growth restriction.

\section{CONFLICT OF INTEREST}

The authors confirm that this article content has no conflict of interest.

\section{ACKNOWLEDGEMENTS}

Declared none.

\section{REFERENCES}

[1] Goldstein JL, Hobbs HH, Brown MS. Familial hypercholesterolemia. In: Scriver CR, Beaud AL, Sly WS, Yalle D, Eds. The metabolic and molecular bases of inherited disease. $8^{\text {th }}$ ed. New York, NY: McGraw-Hill; 2001: pp. 2863-2913.

[2] Austin MA, Hutter CM, Zimmern RL, Humphries SE. Genetic causes of monogenic heterozygous familial hypercholesterolemia: a HuGE prevalence review. Am J Epidemiol 2004; 160: 407-420.

[3] Marks D, Thorogood M, Neil HA, Humphries SE. A review on the diagnosis, natural history, and treatment of familial hypercholesterolaemia. Atherosclerosis 2003; 168: 1-14. 
[4] Austin MA, Hutter CM, Zimmern RL. Familial hypercholesterolemia and coronary heart disease: a HuGE association review. Am J Epidemiol 2004; 160: 421-429.

[5] Yuan G, Wang J, Hegele RA. Heterozygous familial hypercholesterolemia: an underrecognized cause of early cardiovascular disease. CMAJ 2006; 174: 1124-1129.

[6] Raal FJ, Pilcher GJ, Panz VR, et al. Reduction in mortality in subjects with homozygous familial hypercholesterolemia associated with advances in lipid-lowering therapy. Circulation 2011; 124: 2202-2207.

[7] Kolovou GD, Dedoussis GV, Anagnostopoulou KK, et al. Management of a patient with a null low-density lipoprotein receptor mutation: a case report. Angiology 2006; 57: 729-732.

[8] Gagne C, Gaudet D, Bruckert E; Ezetimibe Study Group. Efficacy and safety of ezetimibe co administered with atorvastatin or simvastatin in patients with homozygous familial hypercholesterolemia. Circulation 2002;105: 2469-2475.

[9] Gagne C, Gaudet D, Bruckert E, et al. Ezetimibe significantly reduces low-density lipoprotein cholesterol in homozygous familial hypercholesterolemia. J Am Coll Cardiol 2002; 29: 135B.

[10] Geiss HC, Otto C, Hund-Wissner E, Parhofer KG. Effects of ezetimibe on plasma lipoproteins in severely hypercholesterolemic patients treated with regular LDL-apheresis and statins. Atherosclerosis 2005; 180: 107-112.

[11] Yamamato A, Harada-Shiba M, Endo M, et al. The effect of ezetimibe on serum lipids and lipoproteins in patients with homozygous familial hypercholesterolemia undergoing LDLapheresis therapy. Atherosclerosis 2006; 186: 126-31.

[12] Bruckert E, Gagne C, Gaudet D, et al. Homozygous familial hypercholesterolemia: a novel therapy with ezetimibe. Atherosclerosis 2002; $3: 81$.

[13] Nishimura S, Sekiguchi M, Kano T, et al. Effects of intensive lipid lowering by low-density lipoprotein apheresis on regression of coronary atherosclerosis in patients with familial hypercholesterolaemia: Japan Low-density Lipoprotein Apheresis Coronary Atherosclerosis Prospective Study (LCAPS). Atherosclerosis 1999; 144: 409-417.

[14] Tatami $\mathrm{R}$, Inoue $\mathrm{N}$, Itoh $\mathrm{H}$, et al. Regression of coronary atherosclerosis by combined LDL-apheresis and lipid-lowering drug therapy in patients with familial hypercholesterolaemia: a multicenter study. The LARS Investigators. Atherosclerosis 1992; 95: 1-13.

[15] Thompson GR, Miller JP, Breslow JL. Improved survival of patient 5 with homozygous familial hypercholesterolaemia treated by plasma exchange. Br Med J (Clin Res Ed.) 1985; 291: 1671-3.

[16] Aalders K, Huisman A, Bosker HA. Myocardial infarct in the puerperium. Ned Tijdschr Geneeskd 1998; 142: 1103-5.

[17] Hameed AB, Padmini P, Goodwin TM, et al. Unstable angina during pregnancy in two patients with premature coronary atherosclerosis and aortic stenosis in association with familial hypercholesterolemia. Am J Obstet Gynecol 2000; 182: 1152-5.

[18] Glaser D, Hubert R, Beythien RD, Schuster H, Pawlowitzki H. Fatal re-infarct in pregnancy. Geburtshilfe Frauenheilkd 1988; 48: 656-8.

[19] Wallenburg HCS. Maternal haemodynamics in pregnancy. Fet Med Rev 1990; 2: 45-66.

[20] Barss V, Phillippe M. Greene MF, Covell L. Pregnancy complicated by homozygous hypercholesterolemia. Obstet Gynecol 1985; 65: 756-7.

[21] Beigel Y, Hod M. Fuchs J, et al. Pregnancy in a homozygous familial hypercholesterolemic patient treated with long-term plasma exchange. Am J Obstet Gynecol 1990; 162: 77-8.
[22] Palinski W, Napoli C. The fetal origins of atherosclerosis: maternal Hypercholesterolemia, and cholesterol-lowering or antioxidant treatment during pregnancy influence in utero programming and postnatal susceptibility to atherogenesis. FASEB J 2002; 16: 134860 .

[23] Beigel Y, Bar J, Cohen M, Hod M. Pregnancy outcome in familial homozygous hypercholesterolemic females treated with long-term plasma exchange. Acta Obstet Gynecol Scand 1998; 77: 603-8.

[24] Goldstein BL, Hofshire PJ, Sears TD, et al. Long-term plasmapheresis in the homozygous hyperlipemic patient. Am Heart J 1991; 122: 1465-6.

[25] Cashin-Hemphill L, Noone M, Abbott JF, Waksmonski CA, Les RS. low-density lipoprotein apheresis therapy during pregnancy. Am J Cardiol 2000; 86: 1160, A10.

[26] Anedda S, Mura S, Marcello C, Pintus P. HELP LDL-apheresis in two cases of familial hypercholesterolemic pregnant women. Transfus Apher Sci 2011; 44: 21-4.

[27] Kroon AA, Swinkels DW, van Dongen PWJ, Stalenhoif AF. Pregnancy in a patient with homozygous familial hypercholesterolemia treated with long-term low-density lipoprotein apheresis. Metabolism 1994; 43: 1164-70.

[28] Mora C, Teruel JL, Navarro JF. Low-density lipoprotein apheresis in homozygous familial hypercholesterolemia. Am J Cardiol 2001; 88: 202-3.

[29] Ertorer ME, Guvenc B, Haydardedeoglu B, Tekinturhan F. A case report of the cascade filtration system: a safe and effective method for low-density lipoprotein apheresis during pregnancy. Ther Apher Dial 2008; 12: 396-400.

[30] Blaha M, Lanska M, Boudys L, et al. Pregnancy in homozygous familial hypercholesterolemia- a successful case. Abstracts/Nutrition 2013; 29:1434-6.

[31] Sblinger JL, Brignon P, Grunenberger I. Traitement par LDLapherese au cours de la grossesse. Presse Med 2003; 32: 1031-2.

[32] DeAssis SM, Seguro AC, Helou CM. Effects of maternal hypercho-lesterolemia on pregnancy and development of offspring. Pediatr Nephrol 2003; 18: 328-34.

[33] Thadhani R, Stampfer MJ, Hunter DJ, Manson JE, Solomon CG, Curhan GC. High body mass index and hypercholesterolemia: risk of hypertensive disorders of pregnancy. Obstet Gynecol 1999; 94: 543-50.

[34] Heilmann L, Rath W, Friedrich von Tempelhoff G, et al. Niedermolekulare heparine in der schwangerschaft. Dt. Ärzteblatt 2002; 99/7: C320-C5.

[35] Dittrich E, Schmaldienst S, Langer M, Jansen M, Horl WH, Derfler $\mathrm{K}$. Immunoadsorption and plasma exchange in pregnancy. Kidney Blood Press Res 2002; 25: 232-9.

[36] Swoboda K, Derfler K, Koppensteiner R, et al. Extracorporeal lipid elemination for treatment of gestational hyperlipidemic pancreatitis. Gastroenterology 1993; 104: 1527-31.

[37] Al-Hinai AT, Al-Abri A, Al-Dhuhli $\mathrm{H}$, et al. First case report of familial hypercholesterolemia in an Omani family due to novel mutation in the low- density lipoprotein receptor gene. Angiology 2013; 64: 287-92.

[38] Al-Rasadi K, Al-Waili K, Al-Zidi WA, et al. Low-density lipoprotein receptor gene mutation analysis and structure-function correlation in an Omani Arab family with familial hypercholesterolemia. Angiology 2014; 65: 911-8

[39] Al-Waili K, Al-Zidi WA, Al-Abri AR, et al. Mutation in the PCSK9 gene in Omani Arab subjects with autosomal dominant hypercholesterolemia and its effect on PCSK9 protein structure. Oman Med J 2013; 28: 48-52.

This is an open access article licensed under the terms of the Creative Commons Attribution-Non-Commercial 4.0 International Public License (CC BY-NC 4.0) (https://creativecommons.org/licenses/by-nc/4.0/legalcode), which permits unrestricted, non-commercial use, distribution and reproduction in any medium, provided the work is properly cited. 